\title{
Evidence of the indirect hormonal activity of prohormones using liver S9 metabolic bioactivation and an androgen bioassay
}

\author{
J. C. W. Rijk • T. F. H. Bovee • M. J. Groot • \\ A. A. C. M. Peijnenburg • M. W. F. Nielen
}

Received: 25 April 2008 /Revised: 24 June 2008 / Accepted: 1 July 2008 / Published online: 22 July 2008

(C) The Author(s) 2008

\begin{abstract}
Prohormones such as dehydroepiandrosterone (DHEA) are steroid precursors that do not show hormonal activity by themselves. Abuse of these prohormones in cattle fattening is hard to prove because of strong in vivo metabolism and the difficulty to detect metabolites which are not significantly above endogenous levels. The aim of the present work was to develop an in vitro assay capable of detecting the indirect hormonal activity of prohormones that might be present in feed supplements and injection preparations. Sample extracts were incubated with a bovine liver S9 fraction in order to mimic the in vivo metabolic activation. Subsequently incubated extracts were exposed to a highly androgen-specific yeast bioassay to detect hormonal activity. Metabolic activation of DHEA, 4-androstene-3,17dione (4-adione) and 5-androstene-3,17-diol (5-adiol) resulted in an increased androgenic activity caused by the formation of the active androgen $17 \beta$-testosterone $(17 \beta-\mathrm{T})$, as shown by ultra-performance liquid chromatography and time-of-flight mass spectrometry with accurate mass measurement. The developed in vitro system successfully mimics the hydroxysteroid dehydrogenase (HSD)- and cytochrome P450-mediated in vivo metabolic transitions, thus allowing
\end{abstract}

Electronic supplementary material The online version of this article (doi:10.1007/s00216-008-2275-6) contains supplementary material, which is available to authorized users.

J. C. W. Rijk $(\bowtie) \cdot$ T. F. H. Bovee $\cdot$ M. J. Groot

A. A. C. M. Peijnenburg $\cdot$ M. W. F. Nielen

RIKILT - Institute of Food Safety, Wageningen UR,

P.O. Box 230, 6700 AE Wageningen, The Netherlands

e-mail: jeroen.rijk@wur.nl

M. W. F. Nielen

Laboratory of Organic Chemistry,

Wageningen University,

Dreijenplein 8 ,

6703 HB Wageningen, The Netherlands assessment of both bioactivity and chemical identification without the use of animal experiments. Screening of unknown supplement samples claimed to contain DHEA resulted in successful bioactivation and positive screening results according to the androgen yeast biosensor.

Keywords Bioactivation · Prohormone · Steroid · Bovine · Liquid chromatography $\cdot$ Mass spectrometry

\section{Introduction}

Within the European Union the use of growth-promoting agents in cattle fattening is banned according to EC directive 96/22 [1]. Interestingly, there is not a black list of substances but EC 96/22 states that all substances having thyrostatic, estrogenic, androgenic or gestagenic activity are prohibited. A trend has been observed from the abuse of synthetic steroids towards natural steroid esters and prohormones. Feed supplements and preparations containing prohormones have the potential to enhance the levels of natural occurring steroids and can be misused in livestock production. After administration and uptake in the blood circulation, peripheral tissues are able to metabolize prohormones into more biologically active androgens and estrogens [2-4]. With respect to androgens this leads to anabolic action and subsequently to increased body weight, muscle strength and improved lean/fat ratios in farm animals [5].

Abuse of prohormones in livestock production is hard to prove: urinary metabolites are unknown or not significantly above highly fluctuating endogenous levels [6]. Chemical methods have the drawback of detecting only targeted compounds of interest. Biological transcription activation assays, however, have the advantage of detecting compounds based on bioactivity. For screening of hormones a wide range 
of mammalian or yeast cell-based bioassays have been developed [7-10]. These assays focus mainly on ligandreceptor interactions in which activation of a specific receptor is linked to a transcription reporter mechanism. Assays based on mammalian cell lines are in general more sensitive; however, the metabolic capacity of both mammalian and yeast cellbased assays is rather limited [11-13]. The latter are relatively easy to use and very robust, making them suitable for screening of samples from practice without complex sample cleanup procedures. In addition, yeast cells lack endogenous receptors and thus lack the potential cross talk from other receptor types [14]. As a result the signals obtained in the yeast androgen bioassay may be associated only with the androgenic properties of the compound or sample extract tested.

In vivo, hepatic first pass metabolism of exogenous and endogenous compounds normally leads to inactivation by phase I and phase II enzymes and the subsequent excretion of the deactivated compounds. However, metabolism can also result in an increased biological activity of a given compound [15]. Prohormonal compounds can be activated by hydroxysteroid dehydrogenases (HSDs). Prohormones such as dehydroepiandrosterone (DHEA), 4-androstene3,17-dione (4-adione) and 5-androstene-3,17-diol (5-adiol) are direct precursors of potent androgens like $17 \beta$-testosterone $(17 \beta-T)$ and dihydrotestosterone (DHT). The $3 \beta$-hydroxysteroid dehydrogenase/isomerase ( $3 \beta$-HSD) enzyme catalyzes the two-step conversion of $3 \beta$-hydroxysteroids, like DHEA and 5-adiol, into 4-adione and 17 $\beta$-T, respectively. $17 \beta$-Hydroxysteroid dehydrogenase $(17 \beta-$ HSD) catalyzes the conversion of 17-ketosteroids, like DHEA and 4-adione, into their corresponding 17-hydroxysteroids, 5adiol and $17 \beta-\mathrm{T}$, respectively (Fig. 1). These conversions yield an increase of biological activity in vivo [2-4]. The action of biologically active androgens is mediated by the androgen receptor (AR). Upon ligand binding, the AR dissociates from its chaperone proteins and is translocated in its active state to the nucleus ready to bind to androgenresponsive elements (AREs) [16]. Binding results in recruitment of coactivators and enhanced transcription of target genes regulating androgenic-anabolic action.

In this context we explored the combined use of a bovine liver S9-based bioactivation model and a previously developed highly androgen-specific yeast assay based on the constitutive expression of the human androgen receptor (hAR) in combination with an androgen-responsive element coupled to an enhanced green fluorescent protein (EGFP) reporter system. A promising in vitro model for evidence of the indirect hormonal activity of prohormones, in accordance with the bioactivity-based legislation [1], has been developed. The results obtained were supported by chemical identification of the metabolites using ultra-performance liquid chromatography (UPLC) and time-of-flight mass spectrometry (TOFMS).

\section{Methods and materials}

\section{Chemicals}

Dehydroepiandrosterone (DHEA), 5-androstene-3,17-diol (5adiol), 4-androstene-3,17-dione (4-adione), 17 $\beta$-testosterone



Fig. 1 In vivo steroid hormone biosynthesis: side chain cleavage of cholesterol results in pregnenolone which is metabolized into DHEA under P450c17 activity. From DHEA, conversions are catalyzed by $3 \beta$-HSD and $17 \beta$-HSD activity resulting in formation of potent

androgens like $17 \beta-\mathrm{T}$. Reversible reactions (marked by double arrows) depend on cofactor availability (e.g. NADP/NADPH ratios). Estrogens are formed from androgens (4-adione and $17 \beta-\mathrm{T}$ ) by aromatase activity 
(17 $\beta$-T), $17 \alpha$-testosterone $(17 \alpha-\mathrm{T}), \quad 5 \alpha$-dihydrotestosterone (DHT), $7 \alpha$-hydroxy-DHEA (7 $\alpha$-OH-DHEA), $7 \beta$ hydroxy-DHEA (7 $\beta$-OH-DHEA), 16 $\alpha$-hydroxy-DHEA (16 $\alpha$-OH-DHEA), 16 $\beta$-hydroxy-DHEA (16 $\beta$-OH-DHEA), $11 \beta$-hydroxy-DHEA (11 $\beta$-OH-DHEA) and 19-hydroxyDHEA (19-OH-DHEA) were obtained from Steraloids (Newport, RI, USA). Sodium acetate, sodium carbonate, sodium chloride, di-sodium hydrogen phosphate dihydrate, sodium dihydrogen phosphate monohydrate, ammonium sulphate, magnesium chloride, potassium chloride, tris (hydroxymethyl)aminomethane (Tris), dimethylsulfoxide (DMSO), hydrochloric acid and acetic acid were purchased from Merck (Darmstadt, Germany). Glucose-6-phosphate, NADH disodium salt, NADP disodium salt and NADPH tetrasodium salt were from Roche Diagnostics (Almere, the Netherlands). Acetonitrile, methanol and isooctane were obtained from Biosolve (Valkenswaard, the Netherlands). Dextrose and yeast nitrogen base without amino acids and without ammonium sulphate were from Difco (Detroit, MI, USA). L-Leucine, bovine serum albumin (BSA), hydroxysteroid dehydrogenase originating from Pseudomonas testosteroni and NAD sodium salt were purchased from Sigma (St. Louis, MO, USA). Water used for LC/MS was purified using a Millipore (Bedford, MA, USA) Milli-Q system.

\section{Preparation of liver S9 fractions}

Four Frisian bovines (350-430 kg, 13-14 months old) that served as normally fed negative controls in a 6-week animal experiment were sacrificed at the end of the trial. At sacrifice, liver tissue was rinsed with ice cold $0.9 \%$ sodium chloride and snap-frozen in liquid nitrogen. Liver tissues were homogenized in twice their volume of Tris- $\mathrm{HCl}$ buffer (50 mM, pH 7.4, 1.15\% KCl), using a blender. Homogenates were pooled and centrifuged at $10,000 \mathrm{~g}$ for $25 \mathrm{~min}$ at $4{ }^{\circ} \mathrm{C}$. The supernatant was snap-frozen in liquid nitrogen and stored at $-80{ }^{\circ} \mathrm{C}$ until use. Protein concentrations in this S9 fraction were determined according to Lowry [17], using the BioRad DC protein assay (BioRad, Veenendaal, the Netherlands) and BSA as a standard. The animal experiment referred to was approved by the Animal Ethics Committee of Gent University, Belgium, in accordance with local ethical requirements.

\section{Prohormone incubations}

Incubations of $50 \mu \mathrm{g}$ (pro)hormones, or of $100 \mu \mathrm{l}$ final SPE eluent from supplement samples (see Extraction of supplement samples), were carried out in a glass tube containing $0.1 \mathrm{M}$ sodium phosphate buffer ( $\mathrm{pH} 7.4$ ), $10 \mathrm{mM}$ glucose6-phosphate, $33 \mathrm{mM} \mathrm{KCl}, 8 \mathrm{mM} \mathrm{MgCl}$, $2 \mathrm{mg} / \mathrm{ml}$ bovine S9 fraction and either $4 \mathrm{mM}$ NAD, NADH, NADP or NADPH. The final volume was $1 \mathrm{ml}$ and the mixtures were incubated at $37{ }^{\circ} \mathrm{C}$ in a water bath for $6 \mathrm{~h}$. Single incubations of prohormones and of SPE eluents were performed. Blanks without bovine liver S9 and blanks without cofactor were included to check for nonenzymatic reactions during the incubation period. Reactions were terminated at $t=0$ and $t=6 \mathrm{~h}$ with $1 \mathrm{ml}$ acetonitrile, and the reaction products were subsequently subjected to a cleanup, which is similar to a method described by Marwah et al. [18]. In summary, the mixture was centrifuged for $15 \mathrm{~min}$ at $3,000 \mathrm{~g}$, and the supernatant was transferred to a fresh glass tube. The mixture was extracted again with $2 \mathrm{ml}$ acetonitrile and centrifuged for $10 \mathrm{~min}$ at $3,000 \mathrm{~g}$. The combined supernatants were evaporated under nitrogen at $45{ }^{\circ} \mathrm{C}$ to approximately $0.5 \mathrm{ml}$. Next, the extract was diluted with $3 \mathrm{ml}$ methanol, centrifuged for $15 \mathrm{~min}$ at $3,000 \mathrm{~g}$ and evaporated at $45{ }^{\circ} \mathrm{C}$ under nitrogen until dryness. The residue was dissolved in $200 \mu \mathrm{l}$ methanol and, following the addition of $1.8 \mathrm{ml}$ water, applied onto a preconditioned reversed-phase solid-phase extraction (SPE) cartridge (Waters Oasis ${ }^{\mathrm{TM}}$ HLB, $3 \mathrm{cc}, 6 \mathrm{mg}$ ). The cartridge was washed twice with $2 \mathrm{ml}$ water and eluted with $2 \mathrm{ml}$ methanol. The SPE eluent was evaporated under nitrogen at $45{ }^{\circ} \mathrm{C}$ and reconstituted in $2 \mathrm{ml}$ acetonitrile. Aliquots of $200 \mu \mathrm{l}$ of this final acetonitrile extract plus $50 \mu \mathrm{l} 4 \%$ DMSO were pipetted in a conical 96-well plate (Greiner Bio-One, Germany) and evaporated overnight in a fume cupboard to leave only DMSO the next day.

\section{Extraction of supplement samples}

Two authentic supplement samples were extracted. According to the labels, each capsule of supplement A contained $50 \mathrm{mg}$ DHEA and $10 \mathrm{mg}$ vitamin $\mathrm{C}$ in a base of rice flour, and each capsule of supplement B contained $500 \mathrm{mg}$ Tribulus terrestris, $100 \mathrm{mg}$ 4-androstenedione, $100 \mathrm{mg}$ DHEA, $100 \mathrm{mg}$ lysine and $15 \mathrm{mg}$ zinc amine acid chelate. A 100-mg aliquot of each capsule was extracted according to a method described by Bovee et al. [14]. In summary, sample aliquots were mixed with $4 \mathrm{ml}$ methanol and $4 \mathrm{ml}$ sodium acetate buffer $(0.25 \mathrm{M}, \mathrm{pH} 4.8)$, sonicated for $10 \mathrm{~min}$ and mixed for $15 \mathrm{~min}$ in a head over head apparatus. Samples were then centrifuged for $10 \mathrm{~min}$ at 3,000 rpm, and $4 \mathrm{ml}$ of the supernatant was collected. The $\mathrm{pH}$ of this supernatant was adjusted to $\mathrm{pH} 4.8$ with $4 \mathrm{M}$ acetic acid and applied onto an SPE cartridge (Varian, Bond Elut, C18, $500 \mathrm{mg}, 3 \mathrm{ml}$ ), previously activated with $3 \mathrm{ml}$ methanol and $3 \mathrm{ml}$ sodium acetate buffer. Next, the SPE cartridge was washed with respectively $1.5 \mathrm{ml}$ sodium acetate buffer, $2 \mathrm{ml}$ MilliQ water, $1.5 \mathrm{ml}$ sodium carbonate $(10 \% \mathrm{w} / \mathrm{v}), 2 \mathrm{ml} \mathrm{MilliQ}$ water and $2 \mathrm{ml}$ methanol/water $(50: 50 \mathrm{v} / \mathrm{v})$. The SPE cartridge was dried and eluted with $4 \mathrm{ml}$ acetonitrile. The SPE eluent thus obtained was applied onto an $\mathrm{NH}_{2} \mathrm{SPE}$ cartridge (Isolute, $100 \mathrm{mg}, 3 \mathrm{ml}$ ) 
previously activated with $4 \mathrm{ml}$ acetonitrile. The run through was collected and evaporated at $45{ }^{\circ} \mathrm{C}$ under nitrogen and reconstituted in $4 \mathrm{ml}$ acetonitrile. At this point the SPE eluent is either measured directly in the androgen yeast biosensor or bioactivated according to the procedure as described in Prohormone incubations and then measured by the androgen biosensor. Two sets of spiked supplement samples were prepared to monitor the extraction recovery ("spike before samples") and the potential presence of AR antagonists in the supplements ("spike after samples"). 17ß-Testosterone was added to "spike before samples" $(5 \mu \mathrm{g} / \mathrm{g})$ before the sample preparation step and to "spike after samples" $(30 \mu \mathrm{M}$ in DMSO, $2 \mu \mathrm{l})$ prior to biosensor exposure.

Recombinant yeast androgen bioassay

Transformants of a Saccharomyces cerevisiae strain that express the human androgen receptor (hAR) and an yEGFP reporter system [10] were grown on selective minimal medium plates supplemented with L-leucine. Minimal medium consisted of yeast nitrogen base without ammonium sulphate or amino acids $(1.7 \mathrm{~g} / \mathrm{l})$, dextrose $(20 \mathrm{~g} / \mathrm{l})$, ammonium sulphate $(5 \mathrm{~g} / \mathrm{l})$ and was supplemented with Lleucine $(6 \mathrm{mg} / \mathrm{l})$. At day $1,10 \mathrm{ml}$ minimal medium supplemented with L-leucine $(\mathrm{MM} / \mathrm{L})$ was inoculated with a single colony and cultured overnight at $30{ }^{\circ} \mathrm{C}$, in a shaking incubator at $125 \mathrm{rpm}$. The next day, the overnight culture was diluted in $\mathrm{MM} / \mathrm{L}$ to an optical density (OD) value between 0.04 and 0.06 at $630 \mathrm{~nm}$. Aliquots of $200 \mu \mathrm{l}$ yeast suspension were added to each well of a 96-well plate, already containing the DMSO extract of samples and controls as described in Prohormone incubations. A standard dose-response curve of $17 \beta$-testosterone was included in each experiment. Plates were incubated at $30{ }^{\circ} \mathrm{C}$ for $24 \mathrm{~h}$ in a shaking incubator $(125 \mathrm{rpm})$, and fluorescence was measured (485-nm excitation, 530-nm emission) using a Synergy ${ }^{\mathrm{TM}}$ HT multi-detection microplate reader (BioTek Instruments Inc., USA). The OD of the yeast was measured at $630 \mathrm{~nm}$ after $24 \mathrm{~h}$ to monitor for any cytotoxic effects on the yeast cells.

UPLC-TOFMS assignment of substances formed in metabolic bioactivation

Ultra-performance liquid chromatography (UPLC) was performed on a Waters (Milford, MA, USA) Acquity system containing a Waters Acquity $\mathrm{BEH} \mathrm{C}_{18} 1.7 \mu \mathrm{m}$, $2.1 \times 50$-mm column, with mobile phases (A) acetonitrile/ water/formic acid (10:90:0.2, v/v/v) and (B) acetonitrile/ water/formic acid $(90: 10: 0.2, \mathrm{v} / \mathrm{v} / \mathrm{v})$, linearly increasing from 20 to $46 \% \mathrm{~B}$ in $5 \mathrm{~min}$ at $0.7 \mathrm{ml} / \mathrm{min}$. The column temperature was $45^{\circ} \mathrm{C}$, and the injection volume $20 \mu 1$. The column effluent was split 1:1 prior to mass spectrometry.

Mass spectrometry was performed on a Waters QTOF micro instrument equipped with a dual electrospray ionization (ESI) probe and operated in the positive ion mode (ESI) at a source temperature of $120^{\circ} \mathrm{C}$, desolvation temperature $350{ }^{\circ} \mathrm{C}$, desolvation gas flow $700 \mathrm{l} / \mathrm{h}$, ESI capillary voltage of $3,000 \mathrm{~V}$ and a cone voltage of $30 \mathrm{~V}$. Phosphoric acid in acetonitrile/water (0.01:50:50, v/v/v) was used as reference solution in the LockSpray ${ }^{\mathrm{TM}}$ at a flow rate of $10 \mu \mathrm{l} / \mathrm{min}$. TOF data were collected between $\mathrm{m} / \mathrm{z} 80$ and 1,200 and processed using Masslynx v 4.0 software.

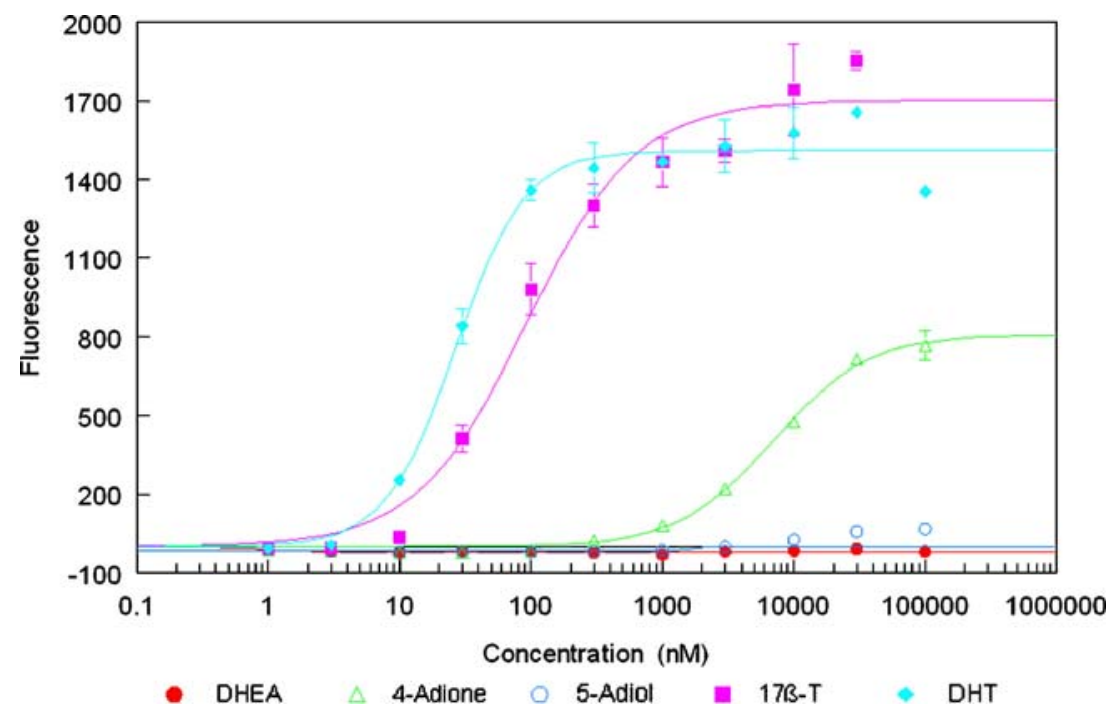

Fig. 2 Dose-response curves of DHEA, 4-adione, 5-adiol, 17ß-T and DHT after $24 \mathrm{~h}$ obtained in the androgen yeast biosensor. Fluorescence signals are the mean of an assay triplicate $( \pm \mathrm{SD})$ and corrected for the signal at $t=0$ and the blank DMSO 


\section{Results and discussion}

Direct androgen bioassay screening

Androgen bioassay dose-response curves of DHEA and known in vivo metabolites 4-androstene-3,17-dione (4adione), 5-androstene-3,17-diol (5-adiol), 17 $\beta$-testosterone $(17 \beta-\mathrm{T})$ and $5 \alpha$-dihydrotestosterone (DHT) are shown in Fig. 2. Nonlinear regression curves were fitted through the data points, and the concentration giving half the maximum $\left(\mathrm{EC}_{50}\right)$ was calculated. Exposure of the androgen reportergene yeast bioassay to DHEA and 5-adiol did not result in a response of the cells, i.e. no direct hormonal activity was observed in vitro in accordance with expectations. In contrast a direct androgenic activity was observed for 4adione, $17 \beta-\mathrm{T}$ and DHT, with $\mathrm{EC}_{50}$ values of $6,900 \mathrm{nM}$, $92 \mathrm{nM}$ and $26 \mathrm{nM}$, respectively. It should be noted that the obtained dose-response curve of 4-adione was also caused by a $17 \beta-T$ impurity (data not shown), apart from the androgenic activity of 4-adione itself.

Incubation of prohormones with bovine liver S9 followed by androgen bioassay screening

To study the bioactivation of prohormones, $50 \mu \mathrm{g}$ of DHEA, 4-adione and 5-adiol were incubated with a bovine liver $\mathrm{S} 9 \mathrm{mix}$ in the presence of either NAD, NADH, NADP or NADPH. Initially, trials were performed with incubations of DHEA with NAD and pure hydroxysteroid dehydrogenase originating from Pseudomonas testosteroni containing $3 \alpha$ - and $3 \beta$-HSD activity. Incubation of DHEA for $1 \mathrm{~h}$ resulted in an increase of response in the androgen yeast assay, caused by formation of 4 -adione and $17 \beta-\mathrm{T}$ (results not shown). However, further work was with bovine liver S9 to include the entire species specific liver metabolism.
Results for sample extracts incubated with the S9 mix for 0 and $6 \mathrm{~h}$ in the presence of $4 \mathrm{mM}$ cofactor and subsequently screened for androgenic activity in the yeast androgen bioassay are shown in Fig. 3. The androgen assay showed no signal for DHEA at $t=0$, but after metabolic activation of DHEA with $\mathrm{S} 9$ in combination with either NAD, NADP or NADPH, an androgenic activity was measured (Fig. 3a). Application of NADH as a cofactor, however, caused only a slight increase in the bioactivity signal.

The compound 4-adione is already androgenic without metabolic activation. Assuming 100\% recovery, the $50 \mu \mathrm{g}$ 4-adione (containing the $17 \beta-\mathrm{T}$ impurity) without activation would result in a final concentration of $87,000 \mathrm{nM}$ in the well, and in accordance with Fig. 2 this resulted in a maximal fluorescence response of about 800. After S9 treatment the signal increased up to maximal 1,200, suggesting that metabolites are formed that are more active than 4-adione itself (Fig. 3b). Figure 3c shows that 5-adiol can be activated by the S9/NAD combination, but no changes in response were found after using NADH, NADP and NADPH as a cofactor. Whether the differences in response found between NAD and NADP are caused by the high level of specificity of HSDs for either NAD or NADP cannot be stated from the present study. The blanks, without bovine liver S9 or cofactor, showed no increase in response after 6-h incubation (results not shown).

Bioactivation plus androgen bioassay screening of supplement samples

Two supplements, A and B, were extracted and screened directly in the yeast androgen bioassay (Fig. 4a and b). In addition, aliquots of both supplements were spiked before extraction with $5 \mu \mathrm{g} 17 \beta$-T per gram sample in order to

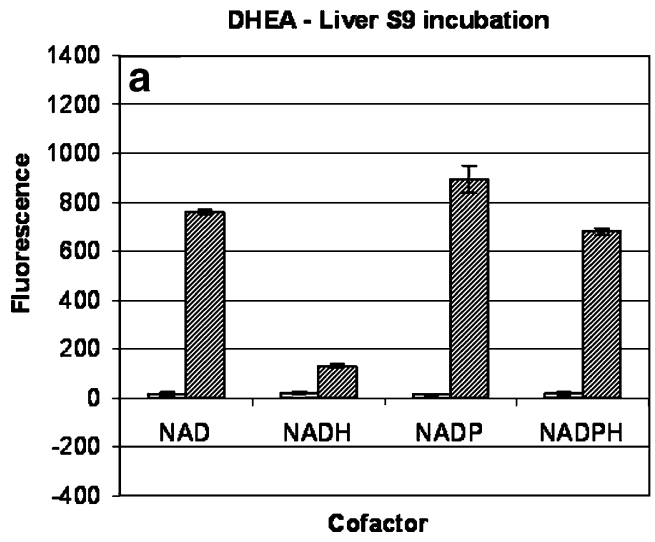

Fig. 3 Androgen bioassay responses of $a$ DHEA, $b$ 4-adione and $c 5$ adiol, before $(t=0)$ and after $(t=6)$ incubation with bovine liver S9 in the presence of different cofactors. Fluorescence signals are the mean
4-Adione - Liver $\mathbf{S 9}$ incubation

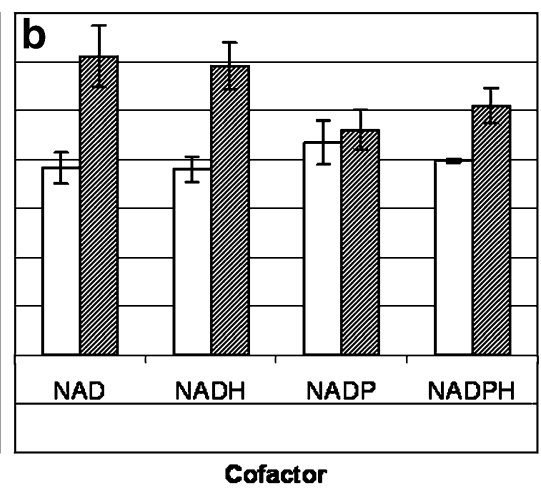

5-Adiol - Liver $\mathbf{S 9}$ incubation

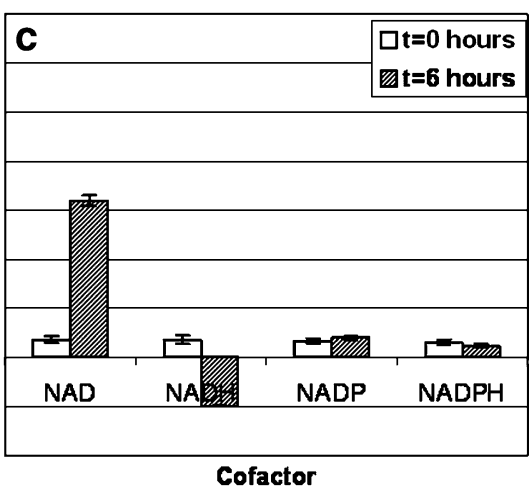

of an assay triplicate $( \pm \mathrm{SD})$ and corrected for the signal at $t=0$ and the reagent blank 
Supplement A

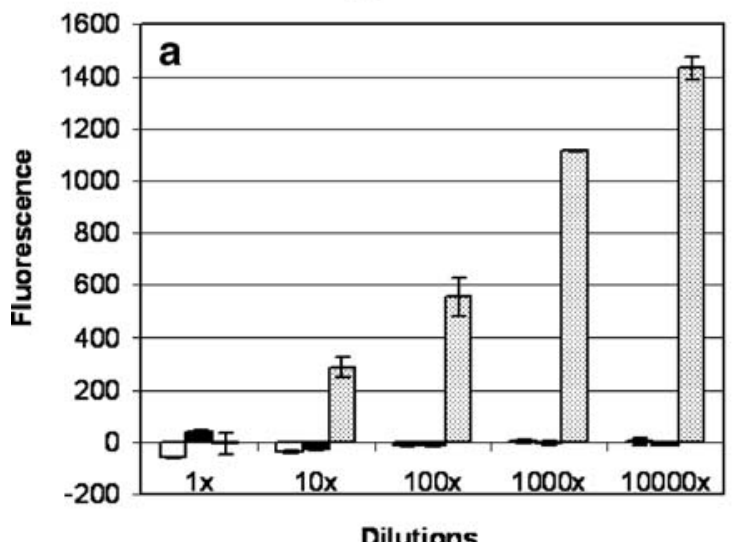

$\square$ Supplement $\square$ Supplement + spike before
Supplement B

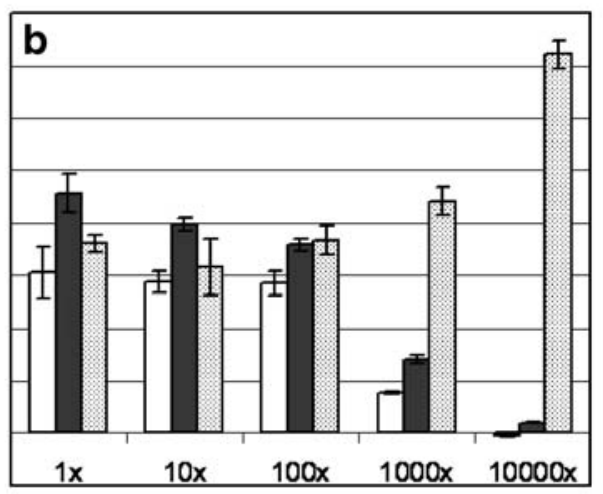

Dilutions
S9 incubation

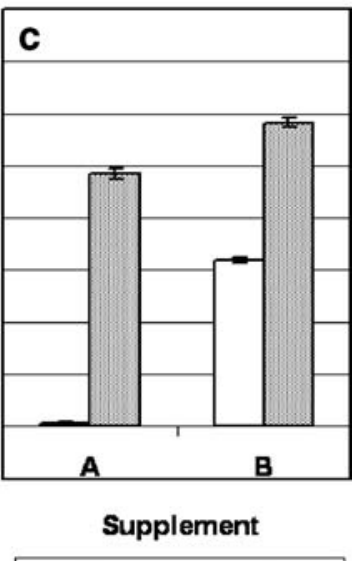

$\square \mathrm{t}=0$ hours $\square \mathrm{t}=6$ hours
Fig. 4 Androgen bioassay responses of $a$ supplement $\mathrm{A}$ and $b$ supplement B as well as spiked with $17 \beta-T$ before $(217 \mathrm{nM}$ in the well, calculated assuming $100 \%$ recovery) and after ( $300 \mathrm{nM}$ added to the well) extraction and cleanup procedure. Fluorescence signals are

\section{$\square$ Supplement + spike after}

the mean of an assay triplicate $( \pm \mathrm{SD})$ and corrected for the signal at $t$ $=0$ and the reagent blank. $c$ Androgen bioassay results after incubation using bovine liver S9 and cofactor NAD check the recovery. Assuming no losses, the $17 \beta-\mathrm{T}$ spike would result in a calculated concentration of $217 \mathrm{nM} 17 \beta-\mathrm{T}$ in the well. After sample cleanup but prior to the androgen bioassay nonspiked sample aliquots were also spiked with $300 \mathrm{nM} 17 \beta-\mathrm{T}$ in the well in order to investigate whether there are any interfering or antagonistic compounds in the extract. According to the dose-response curve shown in Fig. 2, both $17 \beta-T$ spikes are expected to give maximal bioassay response. Supplement A, stated to contain mainly DHEA, did not give a direct androgen bioassay response, but also the $17 \beta-T$ spike before and spike after controls failed to give a response. Dilution of the extract, however, resulted in an increase of the spike after control, suggesting that the extract of this preparation contains an antagonist, which could be DHEA. This is in line with earlier performed quantitative structure-activity relationship (QSAR) modeling approaches, where calculations of the free energy after ligand docking and energy minimization of the ligand-receptor complex were plotted against the relative androgenic potency (RAP) [13]. DHEA showed no androgenic activity, but the calculated free energy is low, suggesting a good binding to the androgen receptor. Thus, DHEA shows affinity for the androgen receptor and might compete with bioactive androgens explaining its antagonistic properties. These antagonistic properties of DHEA were confirmed in the androgen yeast bioassay by coexposure of two concentrations of $17 \beta-T$, one concentration $(70 \mathrm{nM})$ at half maximum and a concentration $(1,000 \mathrm{nM})$ at full androgen bioassay response (data not shown).

Figure $4 \mathrm{~b}$ shows that supplement $\mathrm{B}$ gives a direct androgen bioassay response in accordance with the declared ingredient 4 -adione. This response remains at the same level up to a 100 -fold dilution of the extract, but at a 1,000 -fold dilution the bioassay signal decreases. It should be noted that the "spike after" control does not reach its maximum fluorescence response of about 1,400 and that following dilution of the samples the signal of the "spike after" in the well increases. Again this is due to the antagonistic effects of DHEA, which is also a declared main compound in supplement $B$. Figure $4 c$ shows the androgen bioassay responses of supplement A and B in the yeast androgen bioassay without and after the metabolic activation with the S9/NAD combination. Supplement A does not give a signal without the activation; however, after $6 \mathrm{~h}$ of incubation with bovine liver S9/NAD the signal reaches near maximal response, indicating that bioactive androgenic metabolites have been formed. As mentioned before, supplement B already shows a response; however, after the S9/NAD treatment the signal increases from about 600 to a near maximal response, again indicating that androgenic metabolites have been formed. From these results it can be concluded that supplement A contains proandrogens showing antiandrogenic properties and supplement B contains both androgens and proandrogens containing androgenic and antiandrogenic properties.

\section{UPLC-TOFMS analysis}

UPLC-TOFMS analysis with accurate mass measurement was used for the identification of the metabolites formed after bovine S9 incubation. The metabolites were identified by exact mass measurement and elemental composition calculations thereof, followed by comparison of retention times and mass spectra with the data obtained from 
commercially available standards. Fifty-mDa window reconstructed ion chromatograms were used, being an appropriate window for elemental composition elucidation with a limited chance of false negative results due to mass shifts caused by coeluting isobaric compounds and/or detector saturation [19]. After metabolic activation of DHEA with bovine liver S9 and cofactor NAD (Fig. 5) the main metabolites of DHEA (X) appeared to be 4-adione
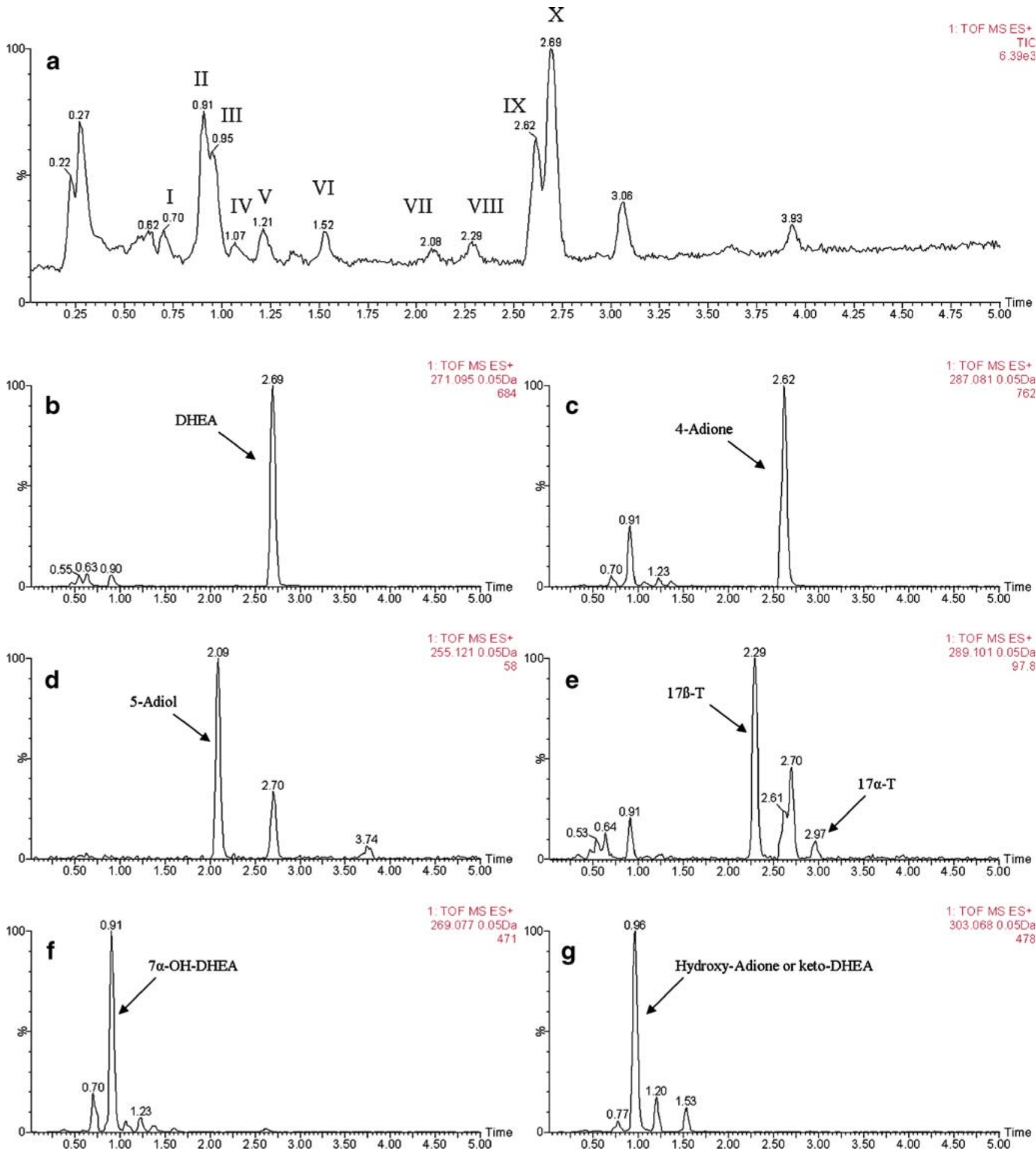

Fig. 5 UPLC-TOFMS total ion current (a) and reconstructed accurate mass chromatograms of DHEA (b), 4-adione (c), 5-adiol (d), $17 \alpha$ - and $17 \beta-\mathrm{T}$ (e), $7 \alpha$-OH-DHEA (f) and a possible hydroxyadione or keto-DHEA metabolite (g) using the accurate mass of the

$[\mathrm{M}+\mathrm{H}]^{+}$or $\left[\mathrm{M}+\mathrm{H}-\mathrm{H}_{2} \mathrm{O}\right]^{+}$ion and a mass window of $0.05 \mathrm{Da}$. Conditions: bovine liver S9 bioactivation using cofactor NAD and an incubation time of $6 \mathrm{~h}$ 
(IX), $7 \alpha$-OH-DHEA (II) and metabolite III at a retention time of $0.95 \mathrm{~min}$ having an abundant ion at $\mathrm{m} / \mathrm{z} 303$ and minor ions at $\mathrm{m} / \mathrm{z} 285$ and $\mathrm{m} / \mathrm{z} 267$ suggesting a ketometabolite of DHEA (e.g. 7-oxo-DHEA) or a hydroxymetabolite of 4-adione. Several minor abundant metabolites eluted after $0.70,1.07,1.21,1.52,2.09$ and $2.29 \mathrm{~min}$ of which the last two appeared to be 5-adiol (VII) and $17 \beta-\mathrm{T}$ (VIII), respectively. The identification of $17 \beta-\mathrm{T}$ and 4adione confirm the bioactivation of DHEA into androgenic substances observed in the androgen bioassay. Metabolites I and IV are most likely hydroxy-metabolites of DHEA resulting in $[\mathrm{M}+\mathrm{H}]^{+}$ions at $\mathrm{m} / z 305$ and $\left[\mathrm{M}-\mathrm{H}_{2} \mathrm{O}+\mathrm{H}\right]^{+}$ions at $m / z$ 287. V and VI most likely are keto-metabolites of DHEA or hydroxylated metabolites of 4-adione, showing $[\mathrm{M}+\mathrm{H}]^{+}$ions at $m / z 303$ and $\left[\mathrm{M}-\mathrm{H}_{2} \mathrm{O}+\mathrm{H}\right]^{+}$ions at $m / z 285$. According to ref. [20] metabolism of DHEA employing human liver S9 for $20 \mathrm{~min}$ (instead of bovine liver S9 for $6 \mathrm{~h}$ ) resulted mainly in $7 \alpha$-OH-DHEA, $7 \beta$-OH-DHEA, 7oxo-DHEA, $16 \alpha$-OH-DHEA and 5 -adiol depending on the cofactor used; no androgenic metabolites like 4-adione and $17 \beta$-T were observed. The retention times of DHEA and its metabolites with corresponding exact masses have been summarized in Table 1. UPLC-TOFMS analysis showed that the spectra of 5-adiol, DHEA and hydroxy-metabolites generally were dominated by $\left[\mathrm{M}+\mathrm{H}-\mathrm{H}_{2} \mathrm{O}\right]^{+}$and $[\mathrm{M}+\mathrm{H}-$ $\left.2 \mathrm{H}_{2} \mathrm{O}\right]^{+}$ions, whereas the base peak in the mass spectra of 4 -adione and $17 \beta-\mathrm{T}$ was the $[\mathrm{M}+\mathrm{H}]^{+}$ion, as expected for 3keto-4-ene steroids [21].

Metabolic activation of 4 -adione, containing a $17 \beta-T$ impurity, with bovine liver $S 9$ resulted in an increase of $17 \beta-T$, thereby confirming the increase in androgen bioactivity as observed in the bioassay. Interestingly $17 \alpha-$ $\mathrm{T}$ was also formed. For 5-adiol, only metabolic activation using NAD resulted in formation of small amounts $17 \beta-T$, in accordance with the bioassay results in Fig. $3 \mathrm{~b}$. The fact that DHEA is converted into 4-adione and 5-adiol and the latter two into $17 \beta-\mathrm{T}$ supports that bovine liver S9 contains $3 \beta-H S D /$ isomerase and $17 \beta$-HSD activity. The observed hydroxy-metabolites of DHEA are due to P450 enzyme activity. Indeed in vitro bovine S9 treatment can mimic the in vivo conversions shown in Fig. 1.

UPLC-TOFMS analysis showed that supplement A contained only DHEA which is in accordance with what is declared on the label. Apart from the claimed DHEA and 4-adione, supplement B contained $17 \beta \beta-T$ and traces of $17 \alpha-\mathrm{T}$, which are possibly by-products formed during production or storage. Metabolic activation of the supplements showed similar metabolite profiles as obtained during activation of DHEA and 4-adione standards, resulting in higher levels of 5-adiol and the more potent androgens 4-adione and $17 \beta-\mathrm{T}$ (see Electronic Supplementary Material).

\section{Conclusions}

This work has outlined the concept of a bioactivity screening assay for prohormones using a combination of bovine liver S9 bioactivation with androgen bioactivity detection. The prohormone DHEA shows no direct androgenic activity in the androgen yeast biosensor but antiandrogenic properties. On the other hand, DHEA, but also 4-adione and 5-adiol, can be converted by bovine S9 into more potent androgens, resulting in an indirect androgenic hormonal activity. The developed in vitro bioactivation system successfully mimics the hydroxysteroid dehydrogenase (HSD)- and cytochrome P450-mediated in vivo metabolic transitions, thus allowing assessment of the indirect bioactivity and chemical identification without the use of animal experiments. UPLC-TOFMS analysis con-

Table 1 UPLC-TOFMS analysis data of DHEA incubated for 6 hours with bovine liver S9/NAD

\begin{tabular}{|c|c|c|c|c|c|c|}
\hline & \multirow[t]{2}{*}{ Retention time $(\min )^{\mathrm{a}}$} & \multicolumn{3}{|l|}{$m / z^{\mathrm{b}}$} & \multirow{2}{*}{$\begin{array}{l}\text { Elemental composition } \\
{[\mathrm{M}+\mathrm{H}]^{+}}\end{array}$} & \multirow[t]{2}{*}{ Identified metabolites $^{\mathrm{c}}$} \\
\hline & & {$[\mathrm{M}+\mathrm{H}]^{+}$} & {$\left[\mathrm{M}-\mathrm{H}_{2} \mathrm{O}+\mathrm{H}\right]^{+}$} & {$\left[\mathrm{M}-2 \mathrm{H}_{2} \mathrm{O}+\mathrm{H}\right]^{+}$} & & \\
\hline I & 0.70 & $305.2117(-0.3)$ & $287.2023(1.2)$ & $269.1928(2.3)$ & $\mathrm{C}_{19} \mathrm{H}_{29} \mathrm{O}_{3}$ & - \\
\hline II & 0.91 & - & $287.2010(-0.1)$ & $269.1905(0.0)$ & $\mathrm{C}_{19} \mathrm{H}_{29} \mathrm{O}_{3}$ & $7 \alpha$-OH-DHEA \\
\hline III & 0.95 & $303.1945(-1.5)$ & $285.1864(0.9)$ & $267.1781(0.9)$ & $\mathrm{C}_{19} \mathrm{H}_{27} \mathrm{O}_{3}$ & - \\
\hline IV & 1.07 & $305.2077(-4.0)$ & $287.2038(2.7)$ & $269.1889(-1.6)$ & $\mathrm{C}_{19} \mathrm{H}_{29} \mathrm{O}_{3}$ & - \\
\hline V & 1.21 & $303.1974(1.4)$ & $285.1855(0.0)$ & - & $\mathrm{C}_{19} \mathrm{H}_{27} \mathrm{O}_{3}$ & - \\
\hline VI & 1.52 & $303.1966(0.6)$ & $285.1858(0.3)$ & $267.1768(1.9)$ & $\mathrm{C}_{19} \mathrm{H}_{27} \mathrm{O}_{3}$ & - \\
\hline VII & 2.08 & - & $273.2220(0.2)$ & $255.2126(1.3)$ & $\mathrm{C}_{19} \mathrm{H}_{31} \mathrm{O}_{2}$ & 5-Androstene-3,17-diol \\
\hline VIII & 2.29 & $289.2197(2.9)$ & - & - & $\mathrm{C}_{19} \mathrm{H}_{29} \mathrm{O}_{2}$ & $17 \beta$-Testosterone \\
\hline IX & 2.62 & $287.1981(-3.0)$ & - & - & $\mathrm{C}_{19} \mathrm{H}_{27} \mathrm{O}_{2}$ & 4-Androstene-3,17-dione \\
\hline $\mathrm{X}$ & 2.69 & $289.2160(-0.8)$ & $271.2049(-1.3)$ & $253.1947(-0.9)$ & $\mathrm{C}_{19} \mathrm{H}_{29} \mathrm{O}_{2}$ & DHEA \\
\hline
\end{tabular}

${ }^{\mathrm{a}}$ Experimental retention times

${ }^{\mathrm{b}}$ Accurate masses of observed ions, with mass error versus the theoretical masses in $\mathrm{mDa}$ (in parenthesis)

${ }^{\mathrm{c}}$ Compounds confirmed by comparison with a standard 
firmed that the tested prohormones are metabolized into the androgenic active steroids 4-adione and $17 \beta$-T. In the same manner other prohormones of androgenic bioactive compounds requiring transformation by HSDs at the 3-position and 17-position can be screened for e.g. the prohormones 19-norandrostenedione and 19-norandrostenediol are expected to be converted into the potent anabolic androgenic steroid nandrolone by $3 \beta-\mathrm{HSD} /$ isomerase and $17 \beta$ HSD activity. In conclusion we can state that the androgen bioassay can be used for the screening of supplements for the presence of androgens, antiandrogens and prohormones, the last of these following liver S9 bioactivation. The system developed is expected to be equally applicable to prohormone preparations from sports doping.

Acknowledgements This project was financially supported by the Dutch Ministry of Agriculture, Nature and Food Quality.

Open Access This article is distributed under the terms of the Creative Commons Attribution Noncommercial License which permits any noncommercial use, distribution, and reproduction in any medium, provided the original author(s) and source are credited.

\section{References}

1. EEC Directive 96/22 (1996) Official J Eur Communities L125:3-9

2. Labrie F (1991) Mol Cell Endocrinol 78:C113-C118

3. Labrie F, Belanger A, Luu-The V, Labrie C, Simard J, Cusan L, Gomez J-L, Candas B (1998) Steroids 63:322-328
4. Lukacik P, Kavanagh KL, Oppermann U (2006) Mol Cell Endocrinol 248:61-71

5. Meyer HHD (2001) APMIS 109:1-8

6. Angeletti R, Contiero L, Gallina G, Montesissa C (2006) Vet Res Commun 30:127-131

7. Blankvoort BMG, de Groene EM, van Meeteren-Kreikamp AP, Witkamp RF, Rodenburg RJT, Aarts JMMJG (2001) Anal Biochem 298:93-102

8. Willemsen P, Scippo M, Maghuin-Rogister G, Martial JA, Muller M (2005) Anal Bioanal Chem 382:894-905

9. Bovee TFH, Helsdingen RJR, Koks PD, Kuiper HA, Hoogenboom LAP, Keijer J (2004) Gene 325:187-200

10. Bovee TFH, Helsdingen RJR, Hamers ARM, van Duursen MBM, Nielen MWF, Hoogenboom LAP (2007) Anal Bioanal Chem 389:1549-1558

11. Soto AM, Maffini MV, Schaeberle CM, Sonnenschein C (2006) Best Pract Res Clin Endocinol 20:15-33

12. Binda D, Lasserre-Bigot D, Bonet A, Thomassin M, Come MP, Guinchard C, Bars R, Jacqueson A, Richert L (2003) Toxicol In Vitro 17:59-67

13. Bovee TFH, Lommerse JPM, Peijnenburg AACM, Antunes Fernandes E, Nielen MWF (2008) J Steroid Biochem 108:121131

14. Bovee TFH, Bor G, Heskamp HH, Hoogenboom LAP, Nielen MWF (2006) Food Addit Contam 23:556-568

15. Coldham NG, Horton R, Byford MF, Sauer MJ (2002) Food Addit Contam 19:1138-1147

16. Gelmann EP (2002) J Clin Oncol 20:3001-3015

17. Lowry OH, Farr Randall RJ (1951) J Biol Chem 193:265-275

18. Marwah A, Marwah P, Lardy H (2002) J Chromatogr B 767:285299

19. Nielen MWF, van Engelen MC, Zuiderent R, Ramaker R (2007) Anal Chim Acta 586:122-129

20. Chalbot S, Morfin R (2005) Drug Metab Dispos 33:563-569

21. Pozo OJ, Van Eenoo P, Deventer K, Delbeke FT (2007) J Mass Spectrom 42:497-516 